\title{
AOR
}

Selected Papers of \#AolR2020:

The $21^{\text {st }}$ Annual Conference of the Association of Internet Researchers

Virtual Event / -31 October 2020

\section{LEGAL AND ETHICAL PERSPECTIVES ON (BIG) DATA, PLATFORMS, AI AND ALGORITHMS}

aline shakti franzke

University Duisburg-Essen

Charles Melvin Ess

University of Oslo

\section{Panel rationale and organization}

Since its inception, the Association of Internet Researchers (AoIR) has fostered critical reflection on the ethical and social dimensions of the internet and internet-facilitated communication. These ethical foci are clearly evoked throughout the thematics of the AolR 2020 conference call, beginning with Power, justice, and inequality in digitally mediated lives; Life, sex, and death vis-à-vis social media; and Political life online.

Concomitantly, Simon Rogerson, Chief Editor of the Journal of Information, Communication and Ethics in Society (JICES), describes JICES as aiming to "...promote thoughtful dialogue regarding the wider social and ethical issues related to the planning, development, implementation and use of new media and information and communication technologies." The Journal thereby offers "necessary interdisciplinary, culturally and geographically diverse works essential to understanding the impacts of the pervasive new media and information and communication technologies."

JICES and AoIR thus share central interests in the ethical and social dimensions of the internet and internet-facilitated communication, and are now collaborating to highlight AolR conference presentations and papers via publication in JICES. As part of this collaboration, we collect here four papers that address these shared interests - with a specific focus on legal and ethical aspects of Big Data. Presuming their acceptance and presentation at AolR 2020, the papers will be revised especially in light of critical responses received there for inclusion in a special issue of JICES devoted to showcasing AolR ethics work.

Suggested Citation (APA): franzke, a., Ess, C. (2020, October 28-31). Legal and Ethical Perspectives on (Big) Data, Platforms, Al and Algorithms. Panel presented at AolR 2020: The 21 th Annual Conference of the Association of Internet Researchers. Virtual Event: AolR. Retrieved from http://spir.aoir.org. 
Paper 1, Towards a Political Theory of Data Justice: A Public Good Perspective, draws on critical data studies and three major political theories of the public good, aiming to synthesize interdisciplinary research on the uses and regulations of digital data in public and political spheres. The authors develop a normative framework outlining the potential public good functions of big data and the necessary normative requirements for the state's rightful collection of large-scale big data, arguing for the state's central role in harnessing large-scale big data to ameliorate digital inequalities and deepen democracy. They offer principles of justice that should guide the regulatory framework of data collection and usage.

\section{Paper 2, Google and Facebook VS Rawls and Lao-Tsu: How Silicon Valley's utilitarianism and Confucianism are bad for Internet ethics, critiques the tech giants' defense of their collection and use of personal data as a questionable consequentialism - one that is further entwined with a Confucian-style hierarchical decision-making. Such consequentialism is easily critiqued: predicting the consequences of acts - in this case, of technological development, adoption, and practices such as online data collection - is demonstrably difficult, if not intrinsically impossible. The paper closes by demonstrating a viable alternative to Silicon Valley's utilitarian hegemony through Rawlsian ethics and Taoist rebuttals of Confucianism.}

Paper 3, The Jurisprudence of Datafied Law, addresses the growing use of data profiles and algorithmic "decision-making" processes in making legal decisions regarding criminal sentencing, parole, bail, and other jurisprudential outcomes. The rule of law queries the capacity of such systems to adequately address the tension in all democratic systems between autonomy and equity. The basic assumptions in such systems also evoke basic questions, i.e., whether such profiles are measurements of static, inherent qualities of the individual, or rather a dynamic social metric against which the subject can assess and potentially improve herself. The latter forces further questions as to the proper role of the state in adopting the datafied tools of "surveillance capitalism" to encourage liberal social orders.

Paper 4, A systematic literature Review of ethical Code of Conduct in the field of Internet Research, notes that since 2017, a broad range of documents concerning the ethics of Al, algorithms and big data have proliferated. These documents have mostly focused on basic values, such as autonomy, privacy and transparency. Other approaches focus more on technological processes, such as the moments of data collection, analyses and disemination. This paper provides an extensive literature review and thereby maps the existing landscape of ethical guidelines for these technologies. A total of 90 documents published between the 2017-2020 are analyzed and organized into a taxonomy. The paper addresses three central questions: How are existing guidelines designed? What types of ethical reasoning do they follow? What sorts of ethical schools are represented?

Both individually and collectively, then, these papers directly take up the central interests shared between AoIR and JICES in the ethical and social dimensions of the internet and internet-facilitated communication. They offer new insight on legal and ethical aspects of contemporary technologies, some of which will have specific implications for internet research ethics. 


\title{
Paper 1: TOWARDS A POLITICAL THEORY OF DATA JUSTICE: A PUBLIC GOOD PERSPECTIVE
}

\author{
Chi Kwok \\ University of Toronto \\ Ngai Keung Chan \\ Cornell University
}

Suggested Citation: Kwok, C., \& Chan, N. C. (2020, October). Towards a political theory of data justice: A public good perspective. Paper presented at AolR 2020: The 21 th Annual Conference of the Association of Internet Researchers. Virtual Event: AolR. Retrieved from http://spir.aoir.org.

\section{Introduction}

Big data simultaneously enables the state's ability to improve its governance for the improvement of people's living conditions and its ability to abuse its power which threatens the privacy and freedom of democratic citizens. The issue becomes more complicated when we account for the ownership and consent of big data (Nissenbaum, 2017). It is under this context that boyd and Crawford (2012) posed two central questions about the relations between big data and politics: (1) whether big data can become a public good that is beneficial to people's well-being and good life, and (2) whether the state should be granted the right to collect big data. These questions still lack a systematic answer in existing big data literature. With qualification, this paper answers yes to these two questions: Big data can be a public good, but the state can only legitimately use and collect them when it fulfills normative conditions of transparency, fairness, and democratic legitimacy.

The contributions of this paper are threefold: first, it develops an interdisciplinary political theory of data justice by connecting three major political theories of the public good (market failure, basic rights, and democratic) (e.g., Kohn, 2020) with empirical studies about the functions of big data (Christin, 2020), thus offering a distinctive perspective explicating why big data should be considered as a public good. Second, it systematically defends the state's right to collect big data from a public good perspective. Third, it offers a normative framework to qualify the conditions under which the state's right to collect big data for beneficial public purposes can be regarded as legitimate. Following Lane et al. (2014), our primary goal is to consider the requirements of justice for "government officials seeking to use big data to serve the public good without harming individual citizens" (p. xi).

\section{Theories of the Public Good and the State's Collection of Big Data}

We examine three major approaches of the public good (market failure, basic rights, and democratic) (Kohn, 2020) to explain why big data should be regarded as a public good.

The market failure approach: This approach suggests that when goods are widely beneficial to the public and yet are not profitable, the inability of the market to provide 
these goods to a sufficient degree renders the state a legitimate reason to provide them (Kohn, 2020). Consider, for example, real-time traffic data. They could inform drivers to avoid traffic congestion and thereby improving road safety, but it would only be widely used by drivers when the data are freely available to them.

The basic rights approach: Shue (1996) argues that goods related to physical security and basic subsistence-because of their paramount significance to the good life of individual citizens - ought to be provided and guaranteed by the state. Consider the example of pandemic data. The Centers for Disease Control and Prevention in the United States has long been collecting data regarding the spread of various diseases and have used these data to advise people to take appropriate preventive measures. Big data for public health purposes can significantly improve prediction speed and precision (Ginsberg et al., 2009), and hence better protect the lives of many.

The democratic approach: This approach points out that "public goods are goods that provided by the 'public' (e.g., the state) to the 'public' (e.g., citizens or residents)" (Kohn, 2020, p.4) for the sake of deepening democracy. An example is that some local governments in the U.S. collaborate with civic technology firms, such as SeeClickFix and Public Stuff, to provide convenient ways for citizens to share data and concerns over local infrastructural problems directly to local governments. Such initiatives not only strengthen local governments' understanding of communal needs, but also incentivize citizens to actively participate in local governance (Graeff, 2018).

\section{Towards a Political Theory of Data Justice}

The paper proposes three central principles of justice in the regulation of the state's collection and uses of big data.

The principle of transparency and accountability: A central worry about the state's collection of big data is that the processes might infringe on individual citizens' privacy and freedom (e.g., Nissenbaum, 2017). Transparent and open processes open possibilities for public surveillance (e.g., the media and civil society) of the state, thus reducing the chance of the state's abusive use of big data. The monitoring of the state's uses of big data requires an active contentious civil society where misbehaviors of the state would be publicly exposed. Thus, the principle requires the state to not only make its own processes of data collection transparent, but also to provide a favorable legal infrastructure for activism against data abuse.

The principle of fairness: The state's collection and uses of big data rely on public finance, and the design of what and how data should be collected is never neutral (Eubanks, 2018). Different designs will result in different social and political groups being benefited. This principle requires the state not only to justify the uses of big data by explaining how it can benefit the public, but also to reasonably explain how the design of data collection does not unfairly skew towards advantaged groups and will not result in negative externalities that harm disadvantaged groups.

The principle of democratic legitimacy: A democratic state's collection and uses of big data can only be legitimate when it is democratically authorized. Given that today's 
governments are increasingly reliant on big data for governance (Desrosières, 2002), it is even more urgent to avoid the state becomes a technocracy (Habermas, 2015) in which political problems are deemed the area belongs to political experts who are capable of understanding and harnessing the power of big data. An ability to see processes of data collection visible is not equated with an ability to know how they work and should be regulated (Ananny \& Crawford, 2018). Therefore, the principle requires not only democratic authorization, but also the massive nurturing of data literacy. A democratic people cannot hold the state accountable to its data abuse and cannot meaningfully authorize the state's collection and uses of big data without understanding what big data is and how it operates.

\section{References}

Ananny, M., \& Crawford, K. (2018). Seeing without knowing: Limitations of the transparency ideal and its application to algorithmic accountability. New Media \& Society, 20(3), 973-989.

boyd, d., \& Crawford, K. (2012). Critical questions for big data: Provocations for a cultural, technological, and scholarly phenomenon. Information, Communication \& Society, 15(5), 662-679.

Christin, A. (2020). What data can do: A typology of mechanisms. International Journal of Communication, 14, 1115-1134.

Desrosières, A. (2002). The politics of large numbers: A history of statistical reasoning. Cambridge, MA: Harvard University Press.

Eubanks, V. (2018). Automating inequality: How high-tech tools profile, police, and punish the poor. New York: St. Martin's Press.

Ginsberg, J., Mohebbi, M., Patel, R. et al. (2009). Detecting influenza epidemics using search engine query data. Nature, 457, 1012-1014.

Graeff, E. (2018). Evaluating civic technology design for citizen empowerment. (Unpublished doctoral dissertation). MIT, Cambridge, MA.

Habermas, J. (2015). The lure of technocracy. Cambridge, UK: Polity.

Kohn, M. (2020). Public goods and social justice. Perspectives on Politics. Advanced online publication. doi: 10.1017/S1537592719004614

Lane, J., Stodden, V., Bender, S., \& Nissenbaum, H. (Eds.) (2014). Privacy, big data, and the public good: Frameworks for engagement. New York, Cambridge University Press.

Nissenbaum, H. (2017). Deregulating collection: Must privacy give way to use regulation? Retrieved from https://papers.ssrn.com/sol3/papers.cfm?abstract id=3092282 


\title{
GOOGLE AND FACEBOOK VS RAWLS AND LAO-TZU: HOW SILICON VALLEY'S UTILITARIANISM AND CONFUCIANISM ARE BAD FOR INTERNET ETHICS
}

\author{
Morten Bay \\ University of Southern California \\ Selected Papers of \#AoIR2020: \\ The 21st Annual Conference of the Association of Internet Researchers \\ Virtual Event / 31 October 2020
}

Suggested Citation: Bay, M. (2020, October). Google and Facebook Vs Rawls and Lao-Tzu: How Silicon Valley's Utilitarianism and Confucianism Are Bad for Internet Ethics. Paper presented at AolR 2020: The 21th Annual Conference of the Association of Internet Researchers. Virtual Event: AolR. Retrieved from http://spir.aoir.org.

\section{Extended Abstract}

The proposed paper presents an argument in favor of a Rawlsian approach to ethics for Internet technology companies (den Hoven \& Rooksby, 2008; Hoffman, 2017). Ethics statements from such companies are analyzed and shown to be utilitarian and teleological in nature, and therefore in opposition to Rawls' theories of justice and fairness. The statements are also shown to have traits in common with Confucian virtue ethics (Ames, 2011; Nylan, 2008).

In contrast to popular perception, American moral philosopher John Rawls did not always denounce consequentialism. He wrote that not taking "consequences into account in judging rightness" would be "irrational, crazy" (Rawls, 1971, p. 30). Rawls' critique of utilitarianism, rather, concerned the extent to which utilitarianism relies on consequentialism and also that it is teleological (Rawls, 1971).

Hence, viewing the technology ethics and guidelines presented by Internet corporations through a Rawlsian lens raises the question: What is more teleological than companies such as Google, Facebook, and their associated platforms, whose business models entail collecting personal user data and making predictions based on these data? Their stated telos is to use the collected data to improve user experiences on services offered to the 
public for free, and to make contributions to a range of public goods from health care to national security through predictive data analytics. Of course, the data sets are also used to predict the effects of commercial and political advertising, which optimizes the companies' shareholder profits (Zuboff, 2015, 2019).

That the justification for the data collection is presented as the benefits outweighing the harms for the biggest number of people demonstrates the teleological and utilitarian approach taken by these technology companies. The companies' ethics statements are often superficial guidelines with very little adherence to actual ethical practice or theory (Microsoft, 2019; Pichai, 2018). By using what the corporations appear to believe are ethical "buzzwords", these ethics statements often resemble Confucian virtue ethics, in that they present virtues to be adopted without rooting these virtues in empirical knowledge, ethical theory or presenting a solidly reasoned argument for them (separating them substantially from the virtue-based technology ethics presented by Ess (2011) and Vallor (2016)). Similar to Confucius presenting the ethical necessity of virtues such as order and propriety as somewhat self-evident, the virtues proposed in tech company ethics statements are contextless and theoretically unmoored (Wong, 2012). The ethics practices of technology companies share a characteristic with Confucian virtue ethics in that the companies enforce strictly hierarchical decisionmaking (Healey \& Woods, 2017). The above-mentioned statements and practices are all contingent on the perceived ability of the technology companies to accurately predict the consequences of their actions and the effect of their products. This confidence in predictions coupled with quasi-Confucianist virtue ethics is yet another demonstration of teleological utilitarianism.

Employing an applied ethics method, public ethics statements from Google, Microsoft, and Facebook are analyzed using the work of two opponents of teleological utilitarianism and Confucianism, John Rawls and Lao-Tzu. More than two thousand years apart, Rawls and LaoTzu both made compelling and strong arguments against employing conjectures about the consequences of decisions and actions as the foundation for decision-making (Lin et al., 2013; Vuong et al., 2018). Lao-Tzu, likely a pseudonym, did so in the classic Taoist text Tao Te Ching, which also contains simple rebuttals of several Confucian virtues. Several arguments emerge from the perspectives of these two philosophers that call the predictionheavy, teleological and consequentialism-based ethics approach of technology companies into question, including the demonstrable difficulty associated with achieving high accuracy in forecasts of technological development, adoption, and practices such as online data collection (Meade \& Islam, 2006).

After showing how the tech industry's utilitarian-Confucian hegemony clashes with Rawlsian ethics and Taoism, these schools of thought are demonstrated as viable alternatives in the construction of technology ethics. The paper argues that these philosophies are particularly viable when considering the ethics of Internet-related technologies, as the communicative, interactive, and participatory nature of the online realm is, arguably, dominated by rapid change.

The speed with which the torrents of changes and transformations flow and thereby constitute the Internet's many domains is not the only thing that makes prediction difficult. 
As Popper (1945) famously pointed out, a constant increase of human knowledge logically leads to a decreased predictability and a heightened risk of unintended consequences being the outcome. In combination, the speed of change, the production of new information, and the proliferation of the latter, makes the Internet a phenomenon characterized much more by unpredictability than, for example, some examples of hardware development. The paper concludes by arguing how these factors demonstrate that Rawlsian, deontological ethics can be a viable alternative to utilitarianism in technology ethics, perhaps even in combination with elements of Taoist thought.

\section{References}

Ames, R. T. (2011). Confucian role ethics: A vocabulary. Chinese University Press.

den Hoven, J., \& Rooksby, E. (2008). Distributive justice and the value of information: A (broadly) Rawlsian approach. Information Technology and Moral Philosophy, 376.

Ess, C. (2011). Ethical dimensions of new technology/media. The Handbook of Communication Ethics, 204-220.

Healey, K., \& Woods, R. H. (2017). Processing is not judgment, storage is not memory: A critique of Silicon Valley's moral catechism. Journal of Media Ethics, 32(1), 2-15. https://doi.org/10.1080/23736992.2016.1258990

Henricks, R. G. (2000). Lao Tzu's Tao Te Ching: A translation of the startling new documents found at Guodian. Columbia University Press.

Hoffman, A. L. (2017). Beyond distributions and primary goods: Assessing applications of Rawls in information science and technology literature since 1990. Journal of the Association for Information Science and Technology, 68(7), 1601-1618. https://doi.org/10.1002/asi.23747

Lin, L.-H., Ho, Y.-L., \& Lin, W.-H. E. (2013). Confucian and Taoist work values: An exploratory study of the Chinese transformational leadership behavior. Journal of Business Ethics, 113(1), 91-103.

Meade, N., \& Islam, T. (2006). Modelling and forecasting the diffusion of innovation - A 25year review. International Journal of Forecasting, 22, 519-545. https://doi.org/10.1016/j.ijforecast.2006.01.005

Microsoft (2019. Our approach: Microsoft Al principles. Microsoft. https://www.microsoft.com/en-us/ai/our-approach-to-ai

Nylan, M. (2008). The five"Confucian" classics. Yale University Press.

Pichai, S. (2018, June 7). Al at Google: Our principles. Google. https://www.blog.google/technology/ai/ai-principles/

Popper, K. (1945). The poverty of historicism, III. Economica, 12(46), 69-89. 
Rawls, J. (1971). A theory of justice. Harvard University Press.

Vallor, S. (2016). Technology and the virtues: A philosophical guide to a future worth wanting. Oxford University Press.

Vuong, Q.-H., et al. (2018). Cultural additivity: Behavioural insights from the interaction of Confucianism, Buddhism and Taoism in folktales. Palgrave Communications, 4(1), 115.

Wong, P.-H. (2012). Dao, harmony and personhood: Towards a Confucian ethics of technology. Philosophy \& Technology, 25(1), 67-86.

Zuboff, S. (2015). Big other: Surveillance capitalism and the prospects of an information civilization. Journal of Information Technology, 30(1), 75-89.

Zuboff, S. (2019). The age of surveillance capitalism: The fight for a human future at the new frontier of power. Profile Books. 